\title{
Brass Mesh Bolus
}

National Cancer Institute

\section{Source}

National Cancer Institute. Brass Mesh Bolus. NCI Thesaurus. Code C160148.

A brass mesh material used to increase the radiation dose at or near the skin surface.

This material is used in place of tissue-equivalent bolus material to achieve improved conformity to the chest wall. 